\title{
Überblick über das Hamburger Burnout-Inventar (HBI)
}

Das Hamburger Burnout-Inventar (HBI) wurde in den neunziger Jahren als erster deutscher Fragebogen zum Thema von Grund auf neu entwickelt. Es bildet die vier Konstrukte der beiden gebräuchlichsten amerikanischen Inventare $a b$, ergänzt durch sechs weitere Konstrukte und ein Einzel-Item, das als grobes Screening-Instrument dienen kann. Insgesamt umfasst das HBI 40 Items; es liefert so mit geringem Aufwand relativ viel differenzierte Information, zumal die Skalen nicht allzu hoch korrelieren. Die Validität für das Kriterium Peer-Ratings wurde in mehreren Studien geprüft, für fast alle Skalen ist sie zumindest zufriedenstellend. Dasselbe gilt für die Innere Konsistenz und die Retest-Reliabilität. Die zehn Rohscores können nichtlinear in Stanines transformiert werden. Die Normstichprobe umfasst 296 Probandinnen und 320 Probanden (insgesamt also 616) und ist vermutlich einigermaßen repräsentativ für deutsche Erwachsene.

Das Instrument, das auch auf Englisch und Französisch vorliegt, wurde von mehr als 300.000 Probanden aus allen Kontinenten der Erde bearbeitet, die freilich wegen Selbstselektion die entsprechenden Populationen nur stark verzerrt vertreten.

Grundlage des HBI ist die Klassische Testtheorie. 